\title{
Interactive comment on "Modeling the paradoxical evolution of runoff in pastoral Sahel. The case of the Agoufou watershed, Mali” by Laetitia Gal et al.
}

J.-E. PATUREL (Referee)
jean-emmanuel.paturel@ird.fr

Received and published: 19 December 2016

you will find my comments in the "supplement" file I upload down

Friendly

Please also note the supplement to this comment:

http://www.hydrol-earth-syst-sci-discuss.net/hess-2016-623/hess-2016-623-RC1-

supplement.pdf

Interactive comment on Hydrol. Earth Syst. Sci. Discuss., doi:10.5194/hess-2016-623, 2016. 